\title{
Generalized cutting force model for peripheral milling of wood, based on the effect of density, uncut chip cross section, grain orientation and tool helix angle
}

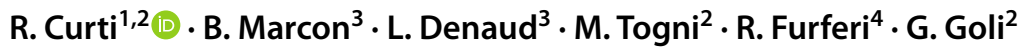

Received: 20 May 2020 / Accepted: 4 February 2021 / Published online: 3 March 2021

(c) The Author(s) 2021

\begin{abstract}
The influence of the grain angle on the cutting force when milling wood is not yet detailed, apart from particular cases (end-grain, parallel to the grain, or in some rare cases $45^{\circ}$-cut). Thus, setting-up wood machining operations with complex paths still relies mainly on the experience of the operators because of the lack of scientific knowledge easily transferable to the industry. The aim of the present work is to propose an empirical model based on specific cutting coefficients for the assessment of cutting force when peripheral milling of wood based on the following input: uncut chip thickness and width, grain angle (angle between the tool velocity vector and the grain direction of the wood), density and tool helix angle. The specific cutting coefficients were determined by peripheral milling with different depths of cut wood disks issued from different wood species on a dynamometric platform to record the forces. Milling a sample into a round shape (a disk) allows to measure the cutting forces toward every grain angle into a sole basic diameter reduction operation. Force signals are then post-processed to carefully clean the natural vibrations of the system without impacting their magnitudes. The experiment is repeated on five species with a large range of densities, machining two disks per species for five depths of cut in up- and down milling conditions for three different tool helix angles. Finally, a simple cutting force model, based on the previously cited parameters, is proposed, and its robustness analysed.
\end{abstract}

\section{Introduction}

The cutting forces on the workpiece observed during wood machining are induced by three main components in the cutting mechanisms: the required new surface generation energy, the friction of the chip on the tool, and the mechanical energy dissipation inside the chip, as clearly presented by Atkins (2005). Marchal et al. (2009) explain how the cutting forces are strongly related to the properties of the final part, for example its roughness as shown by Cyra and Tanaka (2000), which is often very important for the end-user quality appreciation of the product as suggested by the studies by Ramananantoandro et al. (2014) and Ramanakoto et al.

R. Curti

remi.curti@iut-tarbes.fr

1 ICA, University Toulouse III, Toulouse, France

2 DAGRI, University of Florence, Florence, Italy

3 LaBoMaP, Arts Et Metiers Institute of Technology, UBFC, HESAM, Cluny, France

4 DIEF, University of Florence, Florence, Italy
(2017). Moreover, from an engineering point of view, high cutting forces are more likely to introduce tool deflection or vibrations and to increase the defects of the part. Therefore, prior to machining, modelling and simulating of the cutting forces could be a great help for manufacturers in order to set the feed speed and the revolution per minute of the tool to stay within the machine spindle power range, verify their fixture, optimize both the material and cycle time (linked to the energy consumed during the process) as well as the final quality of their production. Tools manufacturers also express their wish to use cutting forces models to run the right tools for the right applications as well as providing the optimized cutting parameters range depending on the operation to perform.

A first attempt to develop a predictive cutting force model for wood machining, the double-beam theory, was initiated by McKenzie (1962). Further contributions were then achieved by developing models using as input wood mechanical properties determined with dynamic tests such as by Eyma et al. (2004), or shear + bending (3-point flexural device) characterization as by Naylor et al. (2012). Eyma tried to relate the specific density $S G$, the elastic modulus 
$E_{c}$, and the hardness $P_{f}$ to the cutting forces while Naylor used the modulus of elasticity $M O E$, the modulus of rupture $M O R$, the shear strength $\tau$, the moisture content $M C$, the toughness $U$, the density $\rho$, and the shear modulus $G$ all together to estimate accurately the cutting forces. The model developed by Eyma was effective to predict cutting forces when machining across the grain using a given multiplicative coefficient to adjust the results for a given wood species. By using more parameters, the model developed by Naylor managed to be independent from the wood species without additional coefficient, both only across and along the grain. However, in both cases, the number of experiments to determine the mechanical parameters to feed the model is large and the models are developed just for one or two cutting directions. More specialized models are dedicated to a single process (for instance, circular sawing), using either analytical or more recently fracture mechanics approaches as from Orlowski et al. (2020). In the case of analytical models, which are most common and easily found in professional books (Wagenführ and Scholz 2012), many correction coefficients are needed to adapt the prediction to different scenarios. In the case where the fracture mechanics is considered, the difficulty comes once again from the empirical determination of the mechanical parameters which can lead to complex and specific experimentations.

All the above-mentioned details illustrate the lack of knowledge concerning the impact of the grain angle $G A$ (i.e. the angle between the cutting tools edge velocity vector and the grain direction of the wood) out of those "main directions" such as parallel or perpendicular to the grain. Although Costes et al. (2004) conducted a study of the cutting forces over a $360^{\circ}$ revolution while turning a wooden sample, the configuration of turning is not directly exploitable for peripheral milling purposes and results cannot be extrapolated. In consequence, this gap still has to be addressed.

Accordingly, the aim of this study is to assess the influences of usual cutting parameters (wood density, uncut chip section, milling mode and tool helix angle) for every grain angle. A preliminary work has been conducted to set up and test the method to acquire the cutting forces and calculate the specific cutting coefficients for materials with well-known properties such as polytetrafluoroethylene (known to be very isotropic) and beech LVL (known to be highly anisotropic) as from Goli et al. (2018). In the present work, a further step is taken by systematizing this procedure for several wood species and using the results computed to propose an empirical cutting forces model based on specific cutting coefficients. Given the strong influence of tool geometry on the cutting forces, this parameter is also studied and analysed through the use of three different tool types: straight blade, and 2 different helix angles $\lambda\left(15^{\circ}\right.$ and $\left.30^{\circ}\right)$.

\section{Materials and methods}

The method consists in machining a wood specimen into a round shape in order to cut it with every possible grain angle. The specimen is fixed on top of a dynamometric platform (type Kistler 9255A) that allows the measurement of the cutting forces, and the platform itself is fixed on the machine worktable. The specimens are machined by peripheral milling (without end-milling). The operation is schematized in Fig. 1.

The method is similar to the experiments imagined by Goli and Sandak (2016) and improved by Goli et al. (2018). The main noticeable improvement from the method presented by Goli et al. (2018) comes from the use of a milling
Fig. 1 Milling operation schematized and definition of the reference system and cutting forces according to Goli et al. (2018)

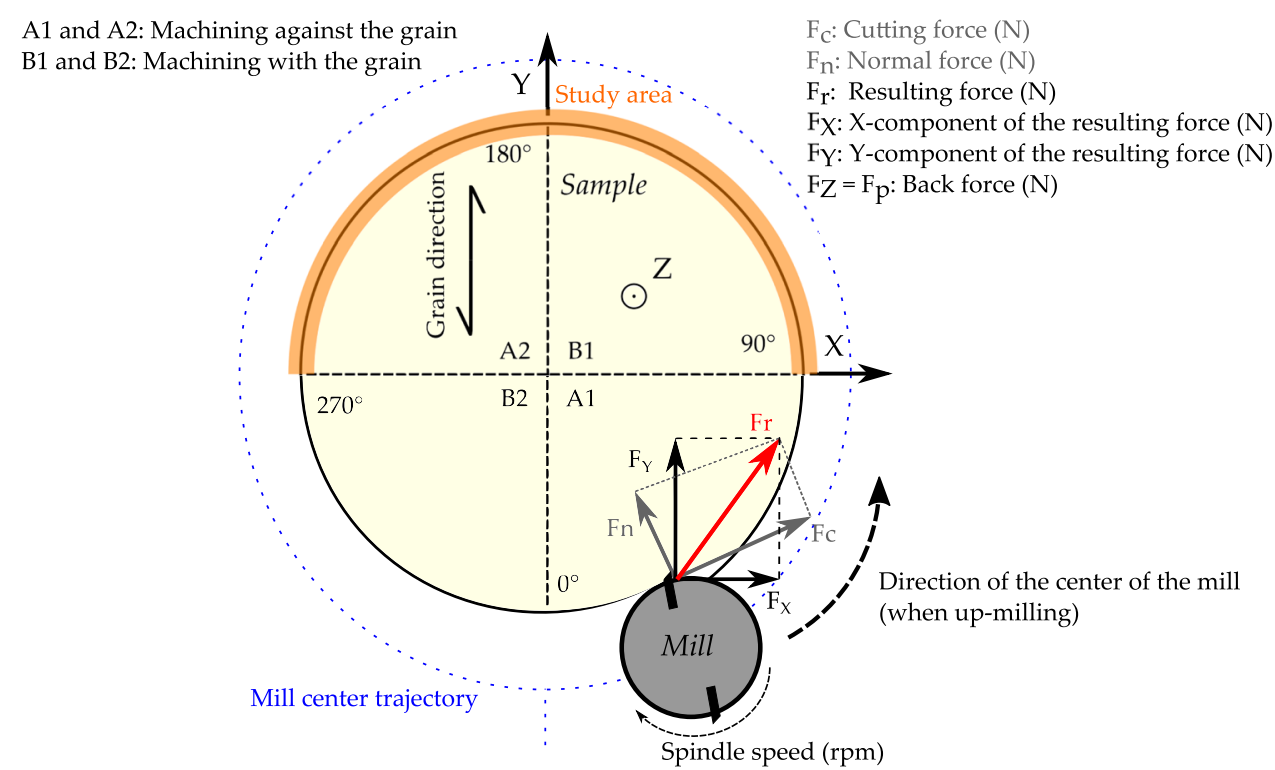


centre for the metal cutting model Alcera 120CR produced by Gambin Corp. The benefit of using a metal cutting machining centre, compared to a router for wood machining as used previously is the stiffer structure that leads to vibrational excitations with a significantly lower amplitude. In addition, this machine is equipped with triggers controlled by a Numerical Control unit which, recorded together with the experimental force signals, allows for an easier synchronization between the tool position and the data acquired during the disk machining.

The main variables of the experiment are: the radial depth of cut, the grain angle, the milling mode (up-milling or down-milling), the type of tool (straight or helical blade), and the material to be cut. To develop a density-based model, 5 wood species ranging from 287.1 to $1079.5 \mathrm{~kg} \mathrm{~m}^{-3}$ are tested and the details are shown in Table 1. Density was measured right after the experiments by weighing 10 control cubes per plank randomly extracted on their volume, while moisture content (MC) was determined by oven dry method according to the standard EN 13183-1 (2002). At the scale of the experiments, all wood species can be considered homogeneous except for paulownia whose growth rings are large enough in relation to the specimen thickness to present a varying ratio between early wood and late wood around the disk. Growth rings of paulownia measure around $10 \mathrm{~mm}$ in the case of the specimens tested, which is not surprising in regard of the literature (Perera et al. 2012). Since it is a fastgrowing tree, even using 30-mm thick specimens did not prevent this variation of ratio in the samples.

Three uncoated, freshly sharpened, tungsten carbide massive tools specially designed for the purpose of the experiment provided by G3 Fantacci Corp (Poggibonsi, Italy) are tested, with a special interest in the effect of the helix angle. Indeed, this parameter is commonly used to reduce the noise of cutting operations and is supposed to reduce the cutting forces by increasing slicing of the chip and increasing the apparent sharpness of the tool edge as detailed by Atkins (2009). To do so, every parameter is kept constant between the tools besides the helix angle. The tools, shown in Fig. 2, are geometrically described in Table 2 .

The machining parameters are gathered in Table 3; every parameter is kept constant during an experiment besides the cutting directions. The feed speed is given at the tool centre; it is recalculated at the tool/material interface for each experiment as it can vary quite a lot both with the tool diameter

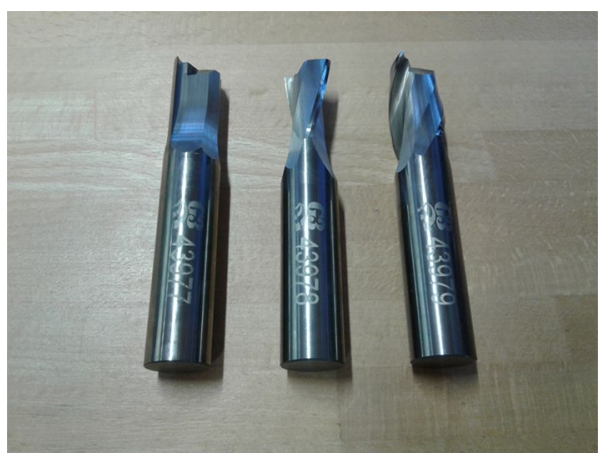

Fig. 2 Mills used during the cutting experiments, from left to right: straight blade, $15^{\circ}$-helical cutter, and $30^{\circ}$-helical cutter

and the diameter variation of the specimen after consecutive experiments/peripheral milling. Five depths of cut $\left(a_{e}\right)$ are tested: $0.5,1.0,1.5,2.0$, and $2.5 \mathrm{~mm}$ to machine with five different uncut chip thicknesses. This results in average uncut chip thicknesses $h$ roughly varying from $40 \mu \mathrm{m}$ (for the smallest depth of cut) to $100 \mu \mathrm{m}$ (for the largest depth of cut).

Prior to the experiment, specimens are disks with a diameter $(\varnothing)$ equal to $250 \mathrm{~mm}$ and a thickness equal to $30 \mathrm{~mm}$; the diameter is progressively reduced after every machining down to a minimum value of $150 \mathrm{~mm}$. Rough specimens machined into a beech slab and ready to be transferred to the experimental setup are illustrated in Fig. 3.

The rough total forces recorded are the forces in the $X$-, $Y$ - and Z-directions (as in Fig. 1) which correspond to the axes of the milling machine and the dynamometric platform. Because of the dynamic excitation of the system, the recorded signals contain undesired vibrations. To solve this problem, as described by Goli et al. (2018), the rough signals are post-processed with a mobile average based on a period of 20 tool revolutions. This technique allows to remove the periodic component of the signal and results in the cutting forces averaged on a tool revolution. The averaged signals are used to calculate the resultant force, which is then projected on the cutting frame (the cutting force being collinear with the cutting direction at the mean uncut chip thickness position; and the normal force, directly orthogonal to the cutting force; as previously represented in Fig. 1). The averaged cutting force referred to the cutting period (instead of the tool revolution) is finally calculated dividing the force

Table 1 Main physical properties of the machined materials (SD in parentheses)

\begin{tabular}{llllll}
\hline Specimen material & $\begin{array}{l}\text { Paulownia (Paulow- } \\
\text { nia tomentosa) }\end{array}$ & Lime (Tilia europaea) & $\begin{array}{l}\text { Maple (Acer pseu- } \\
\text { doplatanus) }\end{array}$ & Oak (Quercus robur) & $\begin{array}{l}\text { Azobe } \\
\text { (Lophira alata) }\end{array}$ \\
\hline Density $\left(\mathrm{kg} / \mathrm{m}^{3}\right)$ & $287.1(3.1)$ & $585.7(7.2)$ & $623.9(5.8)$ & $737.8(12.7)$ & $1079.5(6.4)$ \\
Moisture content $(\%)$ & $8.7(0.2)$ & $8.8(0.1)$ & $9.7(0.1)$ & $11.2(0.8)$ & $11.5(0.9)$ \\
\hline
\end{tabular}


Table 2 Geometrical characteristics of the 3 cutting tools

\begin{tabular}{|c|c|c|c|c|c|c|c|}
\hline Blade type (helix angle $\lambda$ ) & $\begin{array}{l}\text { Diam- } \\
\text { eter } \\
(\mathrm{mm})\end{array}$ & $\begin{array}{l}\text { Number } \\
\text { of flutes/ } \\
\text { teeth } z\end{array}$ & $\begin{array}{l}\text { Rake angle in } \\
\text { the normal plane } \\
\left({ }^{\circ}\right)\end{array}$ & $\begin{array}{l}\text { Wedge angle in } \\
\text { the normal plane } \\
\left({ }^{\circ}\right)\end{array}$ & $\begin{array}{l}\text { Clearance angle in } \\
\text { the normal plane } \\
\left({ }^{\circ}\right)\end{array}$ & Material & $\begin{array}{l}\text { Standard } \\
\text { application } \\
\text { group }\end{array}$ \\
\hline $\begin{array}{l}\text { Straight blade } \\
\left(0^{\circ}\right)\end{array}$ & 20 & 2 & 25 & 55 & 10 & Tungsten Carbide & $\mathrm{O}$ \\
\hline Helical cutter $\left(15^{\circ}\right)$ & 20 & 2 & 25 & 55 & 10 & Tungsten Carbide & $\mathrm{O}$ \\
\hline Helical cutter $\left(30^{\circ}\right)$ & 20 & 2 & 25 & 55 & 10 & Tungsten Carbide & $\mathrm{O}$ \\
\hline
\end{tabular}

Table 3 Machining parameters

\begin{tabular}{lll}
\hline Parameter & Symbol & Value \\
\hline Spindle speed & $\Omega$ & $3000 \mathrm{rpm}$ \\
Feed rate & $V_{f}$ & $2000 \mathrm{~mm} / \mathrm{min}$ \\
Axial depth of cut & $a_{p}$ & $30 \mathrm{~mm}$ \\
Radial depth of cut & $a_{e}$ & $0.5,1.0,1.5,2.0,2.5 \mathrm{~mm}$ \\
\hline
\end{tabular}

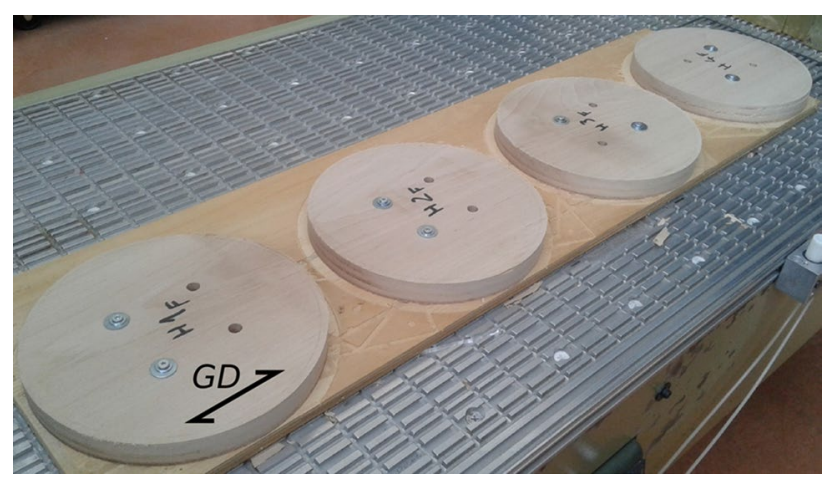

Fig. 3 Four specimens issued from a slab ( $G D$ is the grain direction)

by $(z \times \varphi)$ and multiplying by $(2 \pi)$, where $z$ is the number of blades and $\varphi$ the work angle as the angle travelled by the blade during the cutting of the chip. This method is discussed by Wagenführ and Scholz (2012).

The specific cutting coefficient $(K s)$ is then determined by linear regression over the corrected cutting force for 5 mean uncut chip thicknesses. At the same time, the intercept of the linear regression (Int) is recorded as well for its importance based on the cutting theory by Atkins (2005) which states that this intercept depends on the "toughness" of the material, but this peculiar issue is not subject of further analysis in this particular study. Two replicates were performed for each cutting condition, on two different specimens machined into different slabs; each one providing averaged cutting forces to compute a corresponding specific cutting coefficient $K s$. Then, each pair of $K s$ per cutting condition was averaged to compute a global $K s$ at those cutting conditions. The same process was applied to Int. Those averaged values are only named $K_{s}$ and Int for readability purpose. For the same purpose, $K s$ and Int were computed and averaged over a grain angle span of $1^{\circ}$ but are only displayed every $10^{\circ}$-step.

In the end, two simple models are proposed in order to estimate the cutting force of an operation.

\section{Results and discussion}

\subsection{Cutting forces and specific cutting coefficients of wood with various densities}

Cutting forces and specific cutting coefficients are strongly affected either by the density of the machined wood, the uncut chip thickness, or the grain angle between the grain direction and the cutting speed. Figure 4 displays the evolution of the averaged cutting force normalized on the blade length ( $1 \mathrm{~mm}$-wide chip) toward the grain angle for 5 uncut chip thicknesses when up-milling paulownia (a), lime (b), maple (c), oak (d), and azobe (e) with the $15^{\circ}$ helix angle.

\subsection{Influence of the grain angle (GA)}

The influence of the grain angle is clearly noticeable for every species. A way to represent it is to compute the ratio between the maximum cutting force and the minimum cutting force calculated for each experiment and among the different grain angle. As summed-up in Fig. 5, this ratio varies from 1.34 to 3.73 which depends on the depth of cut, the milling mode, the tool used and the material tested. This ratio (which will be called the degree of anisotropy in the following, not to be confused with a ratio of moduli of elasticity as often used in the construction field) is displayed in Fig. 5 for the five wood species and the two milling modes tested as an average of the values obtained at 5 different uncut chip thicknesses with the three different helical angles. As shown from the low standard deviation, the uncut chip thickness and the tool used for the experiment resulted in negligible impact on the degree of anisotropy.

This ratio is the largest for azobe in up-milling and varies from 2.59 to 3.73 for this species. On the contrary, this effect is the lowest for paulownia in down-milling (from 1.37 to 1.82). However, the average degree of anisotropy for each 

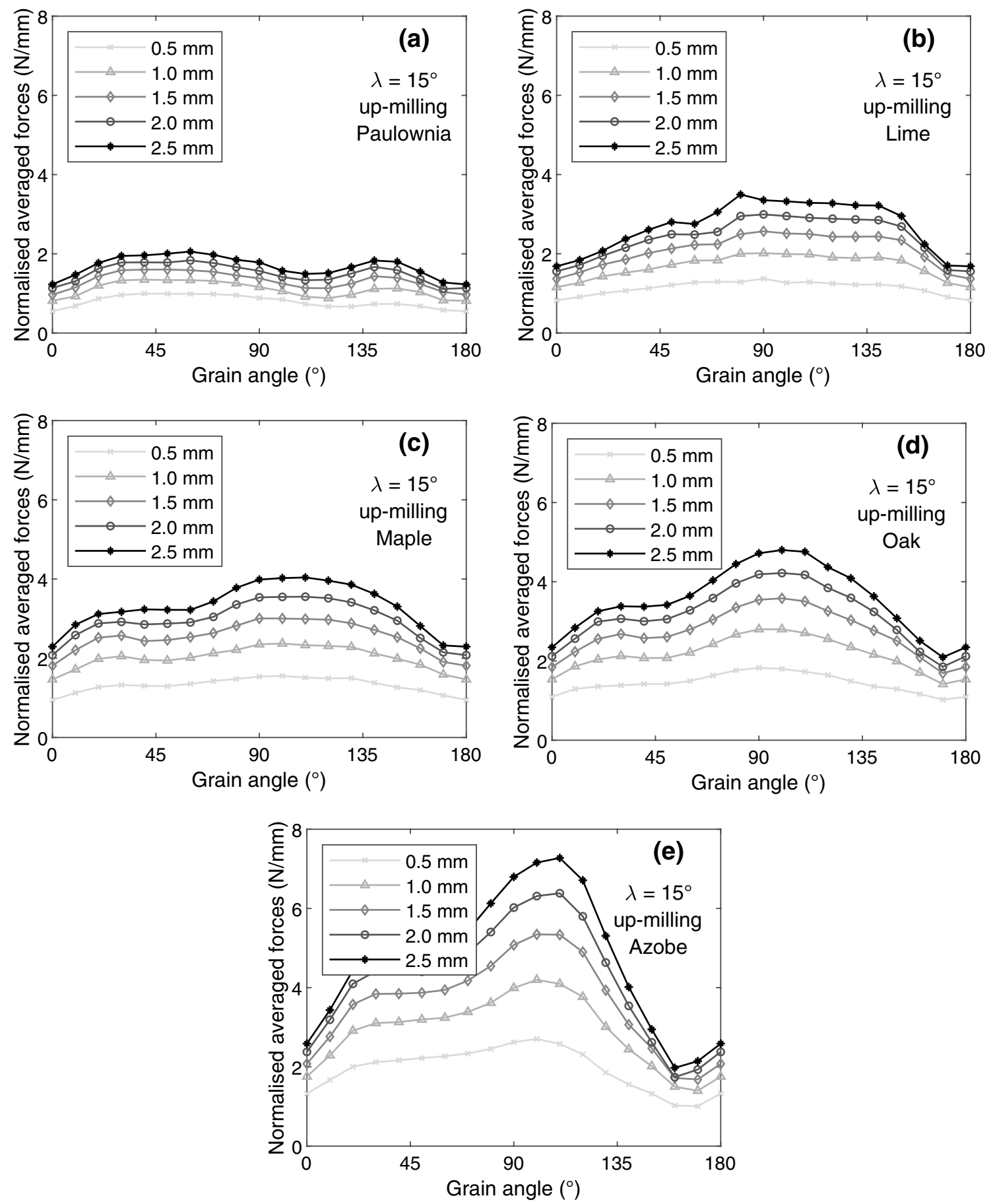

Fig. 4 Cutting forces referred to the grain angle for five radial engagements

species remains slightly below the value of 2 (paulownia: 1.70, lime: 1.87, maple: 1.68, oak: 1.97) except for azobe (its average being 3.38). This strong anisotropy in cutting forces for azobe might not be attributed to the influence of the density but rather to other parameters already known for impacting the wood anisotropy such as the wood material organization at every scale as shown by Thibaut et al.
(2001). Note that during the cutting experiments the authors noticed that the chips were also extremely different depending on the grain angle when cutting azobe. When cutting parallel to the grain only highly fragmented chips and a large quantity of dust were produced while cutting perpendicular to the grain produced continuous chips and a low amount of dust (although not quantified). 


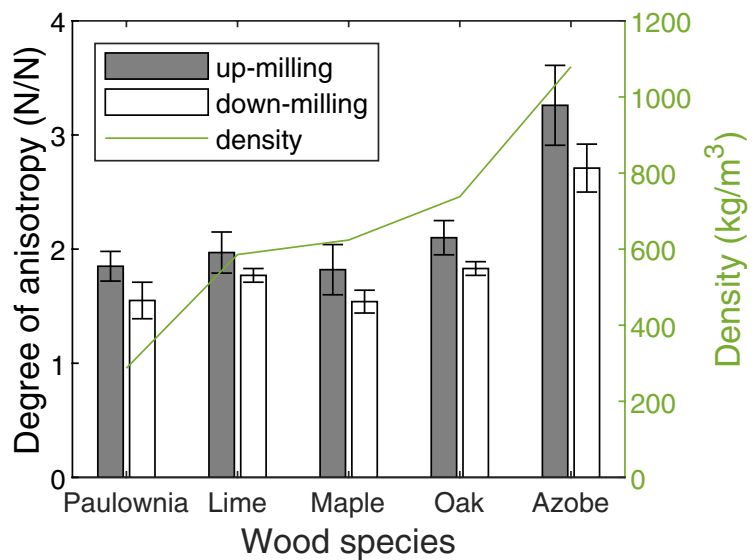

Fig. 5 Average degree of anisotropy of the cutting force according to wood species and the milling mode, over the five depths of cut and three types of tool

The global cutting force variation according to the grain angle displayed in Fig. 4 is comparable whatever the uncut chip thicknesses and wood species, except for paulownia which presents atypical features with two local maxima while only one is present for the 4 other species. However, this observation is likely due to the interaction of two parameters, in the case of paulownia, not only the grain angle varies along the experiment but also the early/late wood ratio as described in the materials and methods section. As stated by Porankiewicz et al. (2007), in cutting conditions presenting highly heterogeneous specimens at the mesoscopic scale, accurate cutting force estimation should take into account the properties of wood locally encountered by the tool. Although this statement is undeniable, the industrial enduser of the model being developed could not be so accurate to consider the local density map of the parts being cut. According to this, in the definition of the model, only the average density of the specimen will be considered. Note that this phenomenon was also observed by the authors during another experimental campaign with poplar wood (not presented here) also for 30-mm-thick specimens and displaying large growth rings as for the tested paulownia.

A linear interpolation, as in Curti et al. (2018) for orthogonal cutting, was applied to uncut chip thickness vs. cutting forces plot and $K_{s}$ and Int parameters determined according to Eq. (1). For all wood species, the coefficient of determination $\left(R^{2}\right)$ between the experimental dataset and this linear interpolation is superior to 0.99 (except for paulownia wood due to its singularity where the average $R^{2}$ was determined to be 0.97$)$.

$F_{C}=\left(K_{s} \times h+I n t\right) \times a_{p}$

In general, the cutting force is minimum when cutting parallel to the grain (grain angle $=0^{\circ}$ ) and rises until

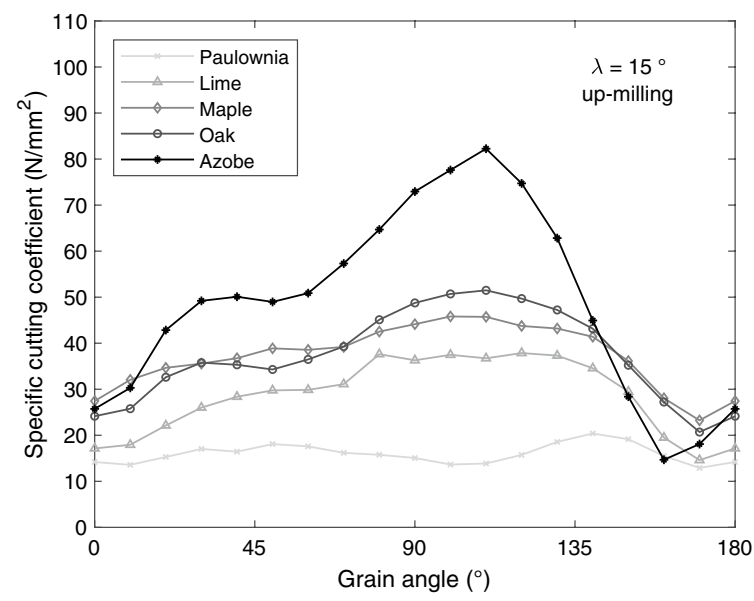

Fig. 6 Specific cutting coefficient $\left(\boldsymbol{K}_{\boldsymbol{s}}\right)$ according to the grain angle when up-milling paulownia, lime, maple, oak, and azobe with the $15^{\circ}$-helical cutter

machining perpendicular to the grain. However, the maximum force is never obtained while cutting strictly perpendicular to the grain but slightly against the grain, when the rake face is parallel to the grain. This was already observed by Goli et al. (2009b), whose results have shown a strong dependency between the maximum cutting forces recorded and the position where the tool rake face and the grain are parallel. Then, the cutting force decreases much faster, machining with the grain, until cutting parallel to the grain again. Thus, the cutting force evolution is not symmetrical from $0^{\circ}$ to $90^{\circ}$ and from $90^{\circ}$ to $0^{\circ}$. Except for paulownia, it is noticeable that the cutting force increase is not perfectly progressive from $0^{\circ}$ to $90^{\circ}$ and slows down around $50^{\circ}$ before rising again.

In practice, the specific cutting coefficient $\left(K_{s}\right)$ is the easiest and most common parameter to be used to calculate the cutting force for any machining scenario and uncut chip section. Thus, it was decided to build the current model based on $K_{s}$. $K_{s}$ has been calculated at every $10^{\circ}$ of grain angle intervals for the whole experimental data. The resulting specific cutting coefficients when up-milling the different species with a $15^{\circ}$-helical cutter are gathered in Fig. 6. This specific cutting configuration has been chosen for the sake of brevity as it constitutes the centre of the whole experimental plan.

The higher the cutting forces the higher the specific cutting coefficient for the five species. Thus, every observation made for cutting forces remains similar for the specific cutting coefficient. The maximum specific cutting coefficient tends to be located around $110^{\circ}$ of grain angle. It is also noticeable that oak and maple display very similar cutting forces and it is even more highlighted when looking at their specific cutting coefficient and intercept. 
The intercepts (Int) corresponding to the previous specific cutting coefficient are displayed in Fig. 7.

The intercept below 0 is mathematically possible but physically surprising as it is supposed to represent the cutting toughness (Atkins 2005). This will be discussed later on after the description of the influence of the tool geometry. The contribution of the intercept to the computed cutting force becomes inferior to 10\% (approximately, since it depends once again on the species) of its value once the uncut chip thickness reaches $100 \mu \mathrm{m}$. In this case, the use of the simplified and popular model (NF E66-520-4 1997), assuming no intercept, could be considered as resumed by Eq. (2):

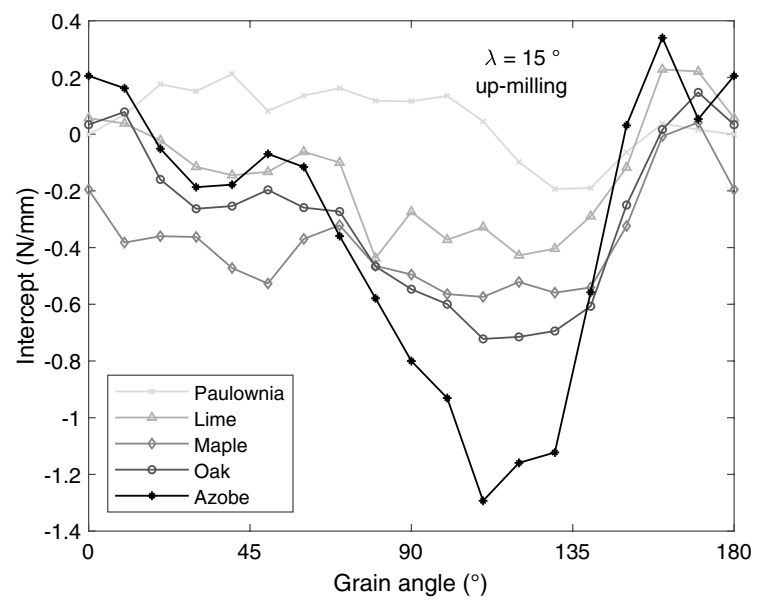

Fig. 7 Intercept (Int) values according to the grain angle when upmilling paulownia, lime, maple, oak, and azobe with the $15^{\circ}$-helical cutter

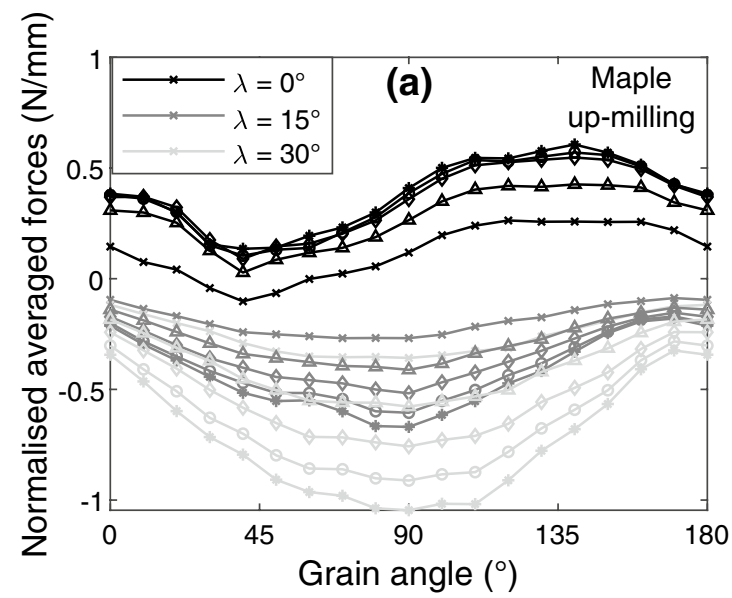

Fig. 8 Back (a) and cutting (b) forces when up-milling maple with different helix angles $\left(\lambda=0^{\circ}, \lambda=15^{\circ}\right.$, and $\left.\lambda=30^{\circ}\right)$. Full circle: $2.5 \mathrm{~mm}$ radial depth of cut, empty circle: $2.0 \mathrm{~mm}$ radial depth of cut,
$F_{C}=K_{s} \times h \times a_{p}$

\subsection{Effect of tool geometry}

To investigate the influence of tool geometry, particular focus must be laid on back force $\left(F_{p}\right)$ addition to the cutting force $\left(F_{c}\right)$. Figure 8 displays, for solid maple, the back force (a) and the cutting force (b) using the three tools described in Table 2 for the 5 depths of cut experimented. Other species are not represented to avoid overloading of figures, but every qualitative observation remains valid for lime, oak, and azobe.

For helical tools, the back force and the cutting force follow exactly the same trends; this is not true for the tool using straight blades. The average back forces with this tool should be null if the geometry of the experimental setup was perfect but they appear slightly negative. However, it remains negligible compared to the cutting forces.

The back forces are the highest for the maximum helix angle $\left(\lambda=30^{\circ}\right)$ whereas cutting forces are maximized when machining with the straight blade $\left(\lambda=0^{\circ}\right)$. Thus, the ratio between back force and cutting force $F_{p} / F_{c}$ increases with the helix angle, which reflects a change in the direction of the resultant force according to the helix angle, and does not appear influenced by the uncut chip thickness in the range studied. Table 4 displays, for the 5 wood species, the average ratio between back force and cutting force regardless of the depth of cut. The ratio seems to be mainly dependent on the type of tool and on the species itself with a lesser impact.

The specific cutting coefficient as well as the intercepts are also modified by the helix angle. This is illustrated in Fig. 9 which focuses separately on the specific cutting

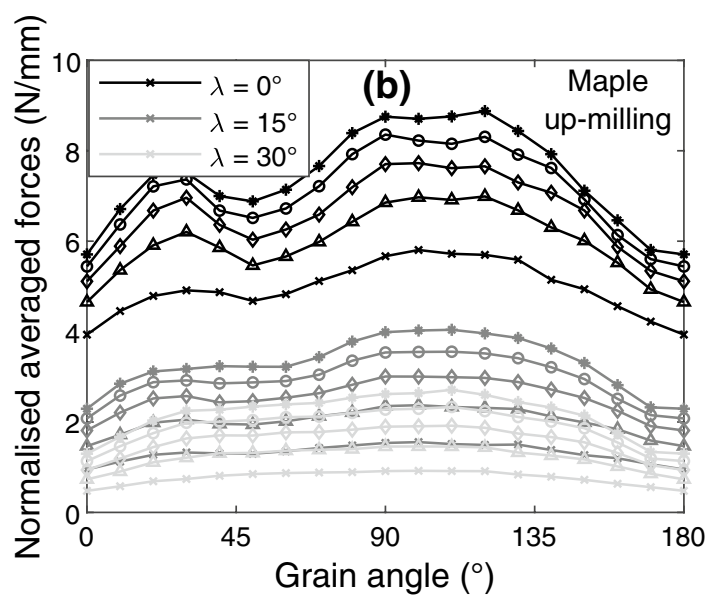

diamond: $1.5 \mathrm{~mm}$ radial depth of cut, triangle: $1.0 \mathrm{~mm}$ radial depth of cut, and crosses: $0.5 \mathrm{~mm}$ radial depth of cut 
Table $4 \boldsymbol{F}_{p} / \boldsymbol{F}_{\boldsymbol{c}}$ ratio averaged for the five depths of cut (SD in parentheses)

\begin{tabular}{llllll}
\hline Helix angle & Paulownia & Lime & Maple & Oak & Azobe \\
\hline$\lambda=0^{\circ}$ & $2.3 \%(1.7 \%)$ & $0.4 \%(2.2 \%)$ & $4.6 \%(2.5 \%)$ & $0.0 \%(2.2 \%)$ & $1.8 \%(1.2 \%)$ \\
$\lambda=15^{\circ}$ & $9.4 \%(2.0 \%)$ & $17.2 \%(3.1 \%)$ & $13.2 \%(3.8 \%)$ & $18.8 \%(2.5 \%)$ & $20.6 \%(2.1 \%)$ \\
$\lambda=30^{\circ}$ & $25.3 \%(4.0 \%)$ & $39.5 \%(4.6 \%)$ & $32.6 \%(6.0 \%)$ & $39.7 \%(4.5 \%)$ & $44.8 \%(4.1 \%)$ \\
\hline
\end{tabular}
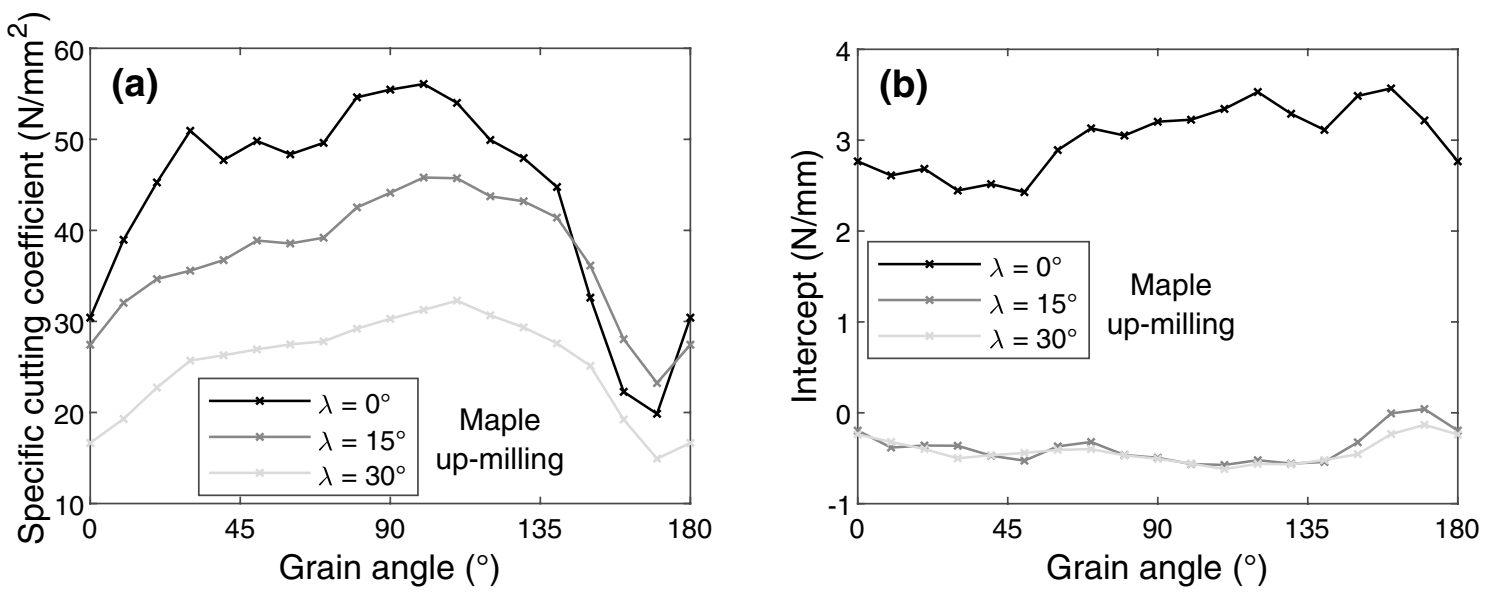

Fig. 9 Specific cutting coefficients (left) and intercepts (right) for maple machining computed for the 3 tools in up-milling configuration

coefficients (a) and the intercepts (b) for the 3 helix angles (tool types).

The intercept is much lower in the case of helical blades for every grain angle and actually close to zero. Thus, the cutting force is directly proportional to the uncut chip thickness, whereas with a straight blade, a constant is present, at least in the range tested. The fact that the intercept is slightly negative makes the empirical model very hazardous to extrapolate for thinner chips since the cutting forces for uncut chip thickness tending to be null are necessarily positive. The model could then be applicable only above the minimal uncut chip thickness measured, which, for a machining operation, can be already considered as very thin.

The fact that the intercept values vary with a property of the tool such as the helix angle could question the Atkins' theory (Atkins 2005) that attributes the intercept value to an intrinsic property of the material such as the toughness.

$K_{s}$ decreases with the helix angle of the tool. The differences are the lowest when cutting parallel to the grain and the largest when machining with the grain. $K_{s}$ is also steadier when using a helical cutter than when milling with a straight blade. This observation can be due to the high dynamic excitation when machining with the straight blade tool. In the present machining set-up, the straight blade tool presents a cutting continuity coefficient (computed as the ratio between the angle during which one blade is actually machining and the angle between two blades of the tool) which varies between 0.1 and 0.2 , depending on the specimen radius and the radial depth of cut. Being this value much lower than 1 , the cut has to be considered as very discontinuous compared to the helical tools (it varies from 0.35 to 0.5 for $\lambda=15^{\circ}$ and from 0.6 to 0.8 for $\lambda=30^{\circ}$ ).

\subsection{Differences observed between up-milling and down-milling}

Cutting forces in down-milling and up-milling follow the same trends. They are displayed in Fig. 10 in the case of a $15^{\circ}$ helical cutter for maple wood.

The most consistent difference lies in the overall lower cutting forces in up-milling with respect to down-milling. Even if the curves in Fig. 10 relate only to the tool with $15^{\circ}$ helix angle, this is also true for 0 and $30^{\circ}$ of helix angle. On average over the 25 configurations tested, forces while upmilling are $9 \%$ lower than during down-milling with a standard deviation of about $4 \%$. This finds its explanation in the fact that in the final part of the cut, the chip splits mainly by crack propagation in front of the cutting edge when up-milling while it must be completely cut when down-milling as previously reported by Koch (1972) and Goli et al. (2009a)

\subsection{Empirical model}

Since in the case of a straight blade cutter or for small chips the intercept value is not negligible, the initial equation, before taking into account the density, is based on Eq. (1) 


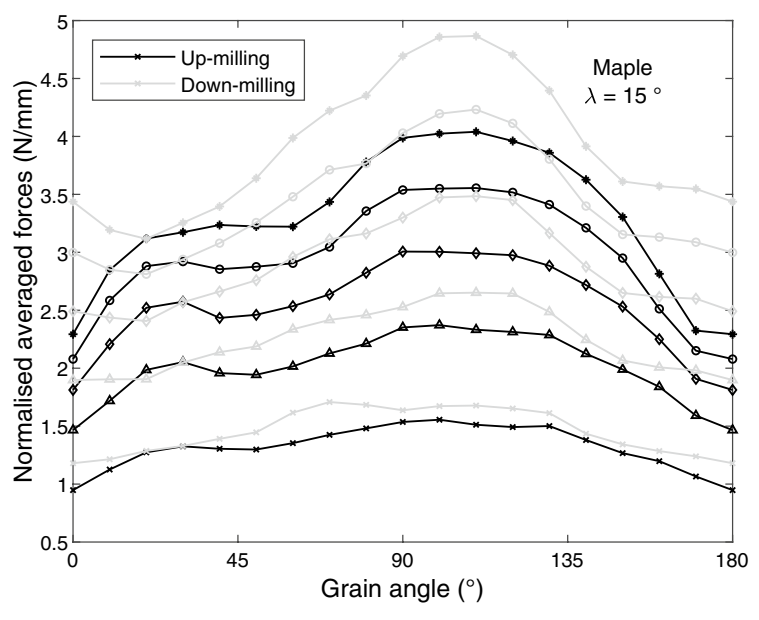

Fig. 10 Cutting force for maple machining computed for up-milling and down-milling using a $15^{\circ}$ helical tool. Full circle: $2.5 \mathrm{~mm}$ radial depth of cut, empty circle: $2.0 \mathrm{~mm}$ radial depth of cut, diamond: $1.5 \mathrm{~mm}$ radial depth of cut, triangle: $1.0 \mathrm{~mm}$ radial depth of cut, and crosses: $0.5 \mathrm{~mm}$ radial depth of cut

and is expressed for one wood species, one tool with a given helix angle $\lambda$, and one grain angle $G A$ as (3):

$F_{c}^{\lambda}(G A)=\left(K_{s}^{\lambda}(G A) \cdot h+i n t^{\lambda}(G A)\right) \cdot A_{p}$

where $F_{c}^{\lambda}(G A)$ is the cutting force for a given tool with a given helix angle $(\lambda)$ for a given wood species and for a given grain angle; $K_{s}^{\lambda}(G A)$ is the specific cutting coefficient for the same configuration; and $i n t^{\lambda}(G A)$ the intercept once again for the same configuration. This empirical model, even if very accurate, suffers from the need of the knowledge of $K_{s}^{\lambda}(G A)$ and $i n t^{\lambda}(G A)$ for every wood species, tool used and grain angle which prevents it from being transferable to the industry. In consequence, it cannot be used, for instance, to predict cutting forces for beech wood. However, based on the hypothesis of a linear influence of the density over the cutting forces variation (often assumed in the literature), the following expression (4) for the cutting force is proposed:

$F_{c}^{\lambda}(G A)=\left(K_{s}^{\lambda, n o r m}(G A) \cdot h+i n t^{\lambda, n o r m}(G A)\right) \cdot A_{p} \times \rho$

where $K_{s}^{\lambda, \text { norm }}(G A)$ is the average specific cutting coefficient for a given angle and a given tool computed as the average of $K_{s}$ determined for the different species after being normalised by the densities, int $t^{\lambda, n o r m}(G A)$ the average intercept for a given angle and a given tool computed as the average of $K_{s}$ determined for the different species after being normalised by the densities and $\rho$ the density of material for which the force must be predicted. It is acknowledged in the literature that the density influence can be considered as linear for a given wood species but that it becomes incorrect when considering several wood species at the same time. Indeed, it is impossible to affirm that for the same densities the effort will be the same between two wood species since mechanical properties are not solely impacted by density, as shown by Gonçalves et al. (1997), but it remains an efficient indicator to use a simple model without in-depth knowledge of the material. Afterwards, $K_{s}^{\lambda, n o r m}(G A)$ and $i n t^{\lambda, n o r m}(G A)$ are represented in Fig. 11, respectively (a) and (c) and (b) and (d) for both up-milling and down-milling configurations and for the three helix angles tested. To allow the calculation of both coefficients for any grain angle and wood density, a model based on a quadratic interpolation of those two parameters is proposed based on the present results. Since the specific cutting coefficient and intercept are not monotonic toward the grain angle variation, and display one global maximum in all the experiments, a quadratic interpolation is a good equilibrium between simplicity of the mathematical model and its accuracy to report the global experimental evolutions.

Both parameters, $K_{s}^{\lambda, \text { norm }}(G A)$ and $i n t^{\lambda, \text { norm }}(G A)$, can be computed for every wood species and grain angle knowing the density of the wood (between 287 and $1080 \mathrm{~kg} / \mathrm{m}^{3}$ to avoid extrapolation) and the grain angle (varying from $0^{\circ}$ to $179^{\circ}$ ) during the operation combining formula (4) and the quadratic fitting equations in Table 5.

To assess the quality of the model suggested, the normalized root-mean-square error (NRMSE) between the force predicted by the model $F_{c_{\text {model }}}(G A)$ and the experiments $F_{c}$ is computed as Eq. (5) for each experiment:

NRMSE $=\frac{\sqrt{\sum_{G A=0}^{180} \frac{\left(F_{c_{\text {model }}}(G A)-F_{c}(G A)\right)}{19}}}{\overline{F_{c}}(G A)}$

This results in 150 NRMSE, one for each experiment (that is to say a set of: one tool, one wood species, one depth of cut and 19 grain angles). Since 5 depths of cut were tested to determine $K_{s}$ with five cutting force measurements, the five NRMSE computed are averaged to obtain only one averaged error for a couple (wood species-helix angle). It is important to notice that this operation is done because the variation of NRMSE is very small from one depth of cut to another for a same couple (wood species-helix angle). The averaged NRMSE obtained for the 30 couples is gathered in Table 6.

The NRMSE cannot capture the fact that the model tends to underestimate or overestimate the cutting force. Based on the observations of the authors, no clear trend can be given, depending on the wood species and the grain angle, it can either underestimate the forces measured or overestimate them. Those errors arise from several factors. The hypothesis of a linear influence on the cutting force with respect to the wood density, averaging the measured specific cutting coefficients and intercept over several wood species, added the use of a quadratic interpolation to compute $K_{s}^{\lambda, n o r m}(G A)$ and $\operatorname{Int} t^{\lambda, n o r m}(G A)$, are three sources of approximations in 

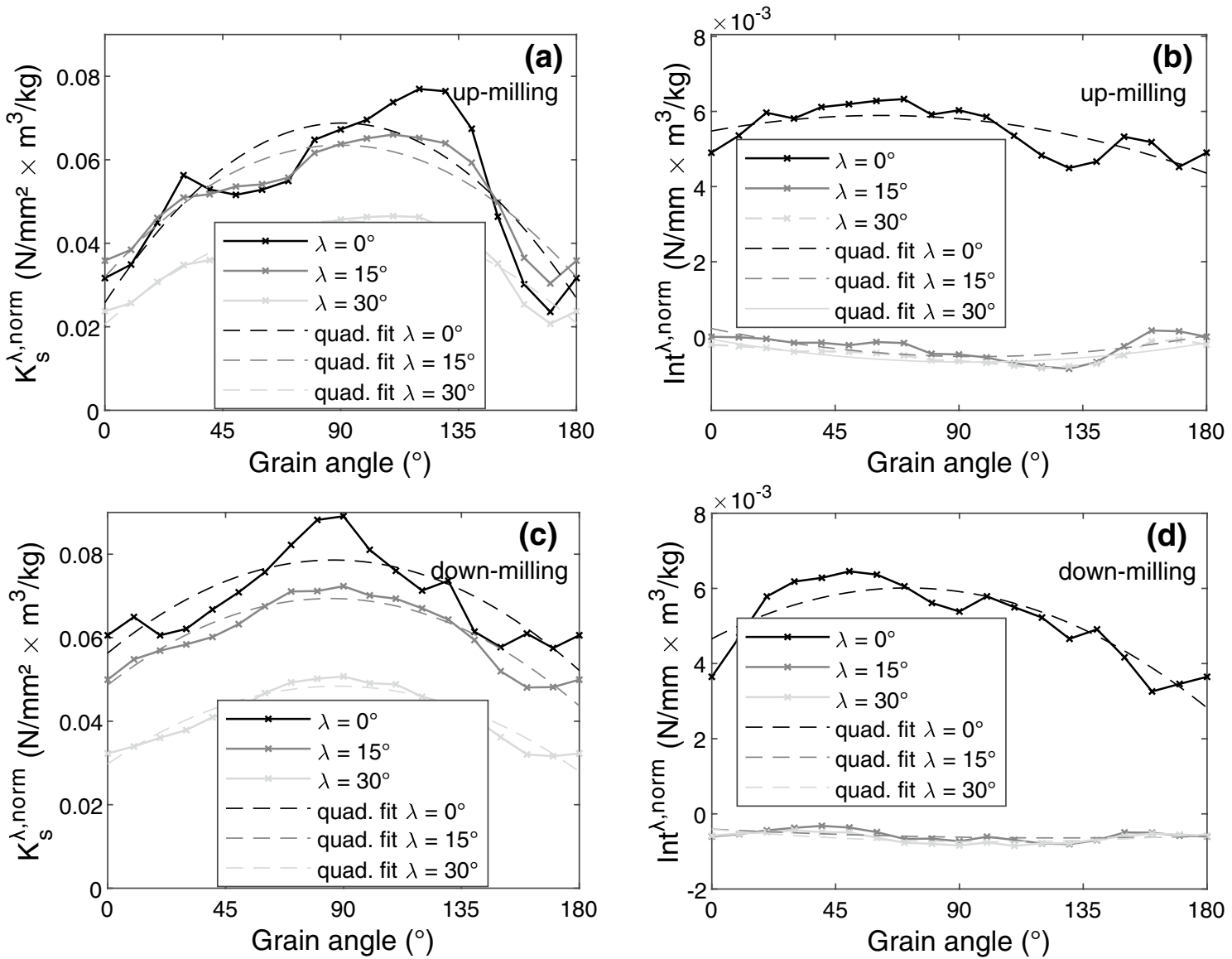

Fig. 11 Specific cutting coefficients and intercepts evolutions averaged for the five wood species machined and divided by the averaged density of the current five wood species in up-milling $\mathbf{a}$ and $\mathbf{b}$ and down-milling $\mathbf{c}$ and $\mathbf{d}$

Table 5 Quadratic model for $\boldsymbol{K}_{\boldsymbol{s}}^{\lambda, \text { norm }}(\boldsymbol{G A})$ and $\boldsymbol{i n t}^{\lambda, \text { norm }}(\boldsymbol{G A}) . \boldsymbol{G A}$ must be expressed in degrees $\left(^{\circ}\right)$

\begin{tabular}{llll}
\hline Milling mode & $\lambda\left({ }^{\circ}\right)$ & $K_{s}^{\lambda, \text { norm }}(G A)$ model & int $^{\lambda, \text { norm }}(G A)$ model \\
\hline Up-milling & 0 & $K_{\text {model }}^{0}=-5 \cdot 10^{-6} G A^{2}+1 \cdot 10^{-3} G A+26 \cdot 10^{-3}$ & Int $_{\text {model }}^{0}=-1 \cdot 10^{-7} G A^{2}+1 \cdot 10^{-5} G A+55 \cdot 10^{-4}$ \\
& 15 & $K_{\text {model }}^{15}=-4 \cdot 10^{-6} G A^{2}+7 \cdot 10^{-4} G A+32 \cdot 10^{-3}$ & Int $_{\text {model }}^{15}=8 \cdot 10^{-8} G A^{2}-2 \cdot 10^{-5} G A+2 \cdot 10^{-4}$ \\
& 30 & $K_{\text {model }}^{30}=-3 \cdot 10^{-6} G A^{2}+5 \cdot 10^{-4} G A+21 \cdot 10^{-3}$ & Int $_{\text {model }}^{30}=7 \cdot 10^{-8} G A^{2}-1 \cdot 10^{-5} G A-6 \cdot 10^{-5}$ \\
Down-milling & 0 & $K_{\text {model }}^{0}=-3 \cdot 10^{-6} G A^{2}+5 \cdot 10^{-4} G A+56 \cdot 10^{-3}$ & Int $_{\text {model }}^{0}=-3 \cdot 10^{-7} G A^{2}+4 \cdot 10^{-5} A+47 \cdot 10^{-4}$ \\
& 15 & $K_{\text {model }}^{15}=-3 \cdot 10^{-6} G A^{2}+5 \cdot 10^{-4} G A+49 \cdot 10^{-3}$ & Int $_{\text {model }}^{15}=1 \cdot 10^{-8} G A^{2}-4 \cdot 10^{-6} G A-4 \cdot 10^{-4}$ \\
& 30 & $K_{\text {model }}^{30}=-2 \cdot 10^{-6} G A^{2}+4 \cdot 10^{-4} G A+30 \cdot 10^{-3}$ & Int $t_{\text {model }}^{30}=3 \cdot 10^{-8} G A^{2}-7 \cdot 10^{-6} G A-4 \cdot 10^{-4}$ \\
\hline
\end{tabular}

Table 6 NRMSE obtained using the model for every species and tool tested

\begin{tabular}{llllrrr}
\hline Milling mode & Helix angle & Paulownia (\%) & Lime $(\%)$ & Maple (\%) & Oak (\%) & Azobe (\%) \\
\hline Up-milling & $\lambda=0^{\circ}$ & 22.34 & 14.38 & 8.10 & 11.52 & 30.29 \\
& $\lambda=15^{\circ}$ & 33.80 & 19.39 & 23.94 & 18.32 & 18.75 \\
\multirow{3}{*}{ Down-milling } & $\lambda=30^{\circ}$ & 19.74 & 8.70 & 8.78 & 9.61 & 22.86 \\
& $\lambda=0^{\circ}$ & 30.65 & 15.29 & 17.58 & 15.46 & 37.82 \\
& $\lambda=15^{\circ}$ & 28.90 & 12.52 & 16.01 & 14.30 & 30.85 \\
& $\lambda=30^{\circ}$ & 19.09 & 18.19 & 9.39 & 10.15 & 29.38 \\
\hline
\end{tabular}

Errors larger than $25 \%$ are in italic font 
the estimation of the proposed model. Since some of the specific cutting coefficients display a local minimum, or at least a steady level, thus displaying 3 inflection points, a 4thdegree polynomial interpolation could lower the errors to the detriment of model simplicity. However, it is still possible to notice that for the most commonly machined wood species of the current dataset, that is to say lime, maple and oak, the NRMSE remains fairly low. The error increases for wood species presenting a lower (paulownia) or higher (azobe) anisotropy of the cutting forces.

\section{Conclusion}

The present work studied the influence of several usual cutting parameters for a whole $180^{\circ}$ range of grain angles. The milling method (up-milling, down-milling) did not influence strongly the cutting forces, although they were consistently lower when up-milling. The tool geometry was investigated using three different tools equipped with straight, $15^{\circ}$-heli$\mathrm{cal}$, and $30^{\circ}$-helical blades. It appears that cutting and resultant forces were lower with helical blades but back forces were higher. The cutting force was found to be directly proportional to the uncut chip thickness using helical blade whereas with the straight blade a non-negligible intercept was found. This phenomenon was not bound to the grain angle and observed over $180^{\circ}$. The impact of the density was also studied. To do so, experiments were run over five wood species with five very different mean densities.. This impact appeared to be noticeable on the averaged cutting forces as expected, and was comparable for all grain angles. An empirical model was suggested considering a linear influence of the density, which generates important errors in cutting force prediction but simplifies a lot the model inputs, which is a criterion to be considered for practical applications. The proposed model allows the calculation of the specific cutting coefficient and intercept for a given machining set-up defined by: the density of the species to be machined, its grain angle and the helix angle of the tool. Once defined the width and the thickness of the chip (the average uncut chip thickness in the case of peripheral milling), the cutting force can be estimated using the specific cutting coefficient and the intercept calculated previously. The model has shown a good predictive accuracy with a maximal NRMSE ranging from 34 or $38 \%$ for the higher and lower densities and with a maximum NRMSE of $24 \%$ for the species with intermediate density.

Acknowledgements Giacomo Goli would like to acknowledge the Art et Metiers Institute of Technology (ENSAM, Cluny campus, France) for financing 2 months in the laboratory LaBoMaP as invited researcher. Rémi Curti would like to acknowledge the European COST Action FP1407 for funding a Short Term Scientific Mission of 1 week at DAGRI during his Ph.D to work with Giacomo Goli. This work was made possible thanks to the funding of the ANISOTROPEE project from the University of Florence (IT) and the support of the Région Bourgogne Franche-Comté (FR). Authors also want to acknowledge Gianluca Fantacci (G3 Fantacci Corp) for designing and providing the three cutting tools used during the core experimental campaign of this study.

Funding Open access funding provided by Università degli Studi di Firenze within the CRUI-CARE Agreement.

\section{Compliance with ethical standards}

Conflict of interest On behalf of all authors, the corresponding author states that there is no conflict of interest.

Open Access This article is licensed under a Creative Commons Attribution 4.0 International License, which permits use, sharing, adaptation, distribution and reproduction in any medium or format, as long as you give appropriate credit to the original author(s) and the source, provide a link to the Creative Commons licence, and indicate if changes were made. The images or other third party material in this article are included in the article's Creative Commons licence, unless indicated otherwise in a credit line to the material. If material is not included in the article's Creative Commons licence and your intended use is not permitted by statutory regulation or exceeds the permitted use, you will need to obtain permission directly from the copyright holder. To view a copy of this licence, visit http://creativecommons.org/licenses/by/4.0/.

\section{References}

Atkins AG (2005) Toughness and cutting: a new way of simultaneously determining ductile fracture toughness and strength. Eng Fract Mech 72:849-860. https://doi.org/10.1016/j.engfracmec h.2004.07.014

Atkins T (2009) The science and engineering of cutting: the mechanics and processes of separating and puncturing biomaterials, metals and non-metals. Butterworth-Heinemann, Oxford. https://doi. org/10.1016/C2009-0-17178-7

Costes JP, Ko PL, Ji T, Decès-Petit C, Altintas Y (2004) Orthogonal cutting mechanics of maple: modeling a solid wood-cutting process. J Wood Sci 50:28-34. https://doi.org/10.1007/s1008 6-003-0527-9

Curti R, Marcon B, Denaud L, Collet R (2018) Effect of grain direction on cutting forces and chip geometry during green beech wood machining. BioResources 13:5491-5503. https://doi.org/10.15376 /biores.13.3.5491-5503

Cyra G, Tanaka C (2000) The effects of wood-fiber directions on acoustic emission in routing. Wood Sci Technol 34:237-252. https:// doi.org/10.1007/s002260000043

EN 13183-1:2002 (2002) Moisture content of a piece of sawn timber determination by oven dry method. European Committee for Standardization (CEN), Brussels

Eyma F, Méausoone PJ, Martin P (2004) Study of the properties of thirteen tropical wood species to improve the prediction of cutting forces in mode B. Ann For Sci 61:55-64. https://doi.org/10.1051/ forest:2003084

Goli G, Sandak J (2016) Proposal of a new method for the rapid assessment of wood machinability and cutting tool performance in peripheral milling. Eur J Wood Prod 74:867-874. https://doi. org/10.1007/s00107-016-1053-y

Goli G, Fioravanti M, Marchal R, Uzielli L (2009a) Up-milling and down-milling wood with different grain orientations « theoretical 
background and general appearance of the chips. Eur J Wood Prod 67:257-263. https://doi.org/10.1007/s00107-009-0323-3

Goli G, Fioravanti M, Marchal R, Uzielli L, Busoni S (2009b) Up-milling and down-milling wood with different grain orientations- the cutting forces behaviour. Eur J Wood Prod 68:385-395. https:// doi.org/10.1007/s00107-009-0374-5

Goli G, Curti R, Marcon B, Scippa A, Campatelli G, Furferi R, Denaud L (2018) Specific cutting forces of isotropic and orthotropic engineered wood products by round shape machining. Materials 11:2575. https://doi.org/10.3390/ma11122575

Gonçalves MTT, Rodrigues R, Takahashi JSI et al. (1997) An experimental analysis of the influences of machining conditions on the parallel cutting force in orthogonal cutting for ten Brazilian wood species. In: Proceedings of the 13th International Wood Machining Seminar 491-498

Koch (1972) Utilization of the southern pines. Agriculture Handbook no. 420, US Southern Forest Experiment Station

Marchal R, Mothe F, Denaud LE, Thibaut B, Bleron L (2009) Cutting forces in wood machining-basics and applications in industrial processes. A review. COST Action E35 2004-2008: Wood machining - Micromechanics and fracture. Holzforschung 63:157-167. https://doi.org/10.1515/HF.2009.014

McKenzie WM (1962) The relationship between the cutting properties of wood and its physical and mechanical properties. For Prod J 12:287-294

Naylor A, Hackney P, Perera N, Clahr E (2012) A predictive model for the cutting force in wood machining developed using mechanical properties. Bio Resour 7:2883-2894

NF E66-520-4 (1997) Domaine de fonctionnement des outils coupants couple outil-matière. Partie 4 : mode d'obtention du couple outilmatière. AFNOR, Bobigny

Orlowski KA, Ochrymiuk T, Hlaskova L, Chuchala D, Kopecky Z (2020) Revisiting the estimation of cutting power with different energetic methods while sawing soft and hard woods on the circular sawing machine: a Central European case. Wood Sci Technol 54:457-477. https://doi.org/10.1007/s00226-020-01162-9

Perera P, Amarasekera H, Weerawardena NDR (2012) Effect of growth rate on wood specific gravity of three alternative timber species in Sri Lanka, Swietenia macrophylla, Khaya senegalensis and Paulownia fortune. J Trop For Environ. https://doi.org/10.31357 /jtfe.v2i1.567

Porankiewicz B, Bermudez JC, Tanaka C (2007) Cutting forces by peripheral cutting of low density wood species. Bio Resour 2:671-681

Ramanakoto MF, Andrianantenaina AN, Ramananantoandro T, Eyma F (2017) Visual and visuo-tactile preferences of Malagasy consumers for machined wood surfaces for furniture: acceptability thresholds for surface parameters. Eur J Wood Prod 75:825-837. https://doi.org/10.1007/s00107-016-1098-y

Ramananantoandro T, Larricq P, Eterradossi O (2014) Relationships between 3D roughness parameters and visuotactile perception of surfaces of maritime pinewood and MDF. Holzforschung 68:93101. https://doi.org/10.1515/hf-2012-0208

Thibaut B, Gril J, Fournier M (2001) Mechanics of wood and trees: some new highlights for an old story. Comptes Rendus Académie Sci Ser IIB Mech 329:701-716. https://doi.org/10.1016/S1620 -7742(01)01380-0

Wagenführ A, Scholz F (2012) Taschenbuch der Holztechnik. (Pocketbook of wood technology) (In German). Fachbuchverlag, Leipzig. https://doi.org/10.3139/9783446431799

Publisher's Note Springer Nature remains neutral with regard to jurisdictional claims in published maps and institutional affiliations. 